\title{
REMEDIAL WORKS AND REPAIRS OF HISTORICAL BRIDGE IN PRAGUE
}

\author{
Iva Broukalová ${ }^{\bigotimes}$, Vladimír Krrístek ${ }^{2}$ \\ Dept of Concrete and Masonry, Faculty of Civil Engineering, Czech Technical University in Prague Structures, \\ Thákurova, 7, Prague 6, 166 29, Czech Republic \\ E-mails: ${ }^{1}$ iva.broukalova@fsv.cvut.cz; ${ }^{2}$ kristek@fsv.cvut.cz
}

\begin{abstract}
The recent reconstruction of the historical masonry Charles Bridge in Prague was designed with respect to original conception, materials and ancient construction techniques. The repair and remedial works were based on analysis of the multi-decade response of the bridge, diagnosis, and assessment of damages, failures and deterioration processes related to materials, environment, climate, structural arrangement and detailing regarding heritage, historical and structural aspects. The gentle way of remedial works with minimal intervention in the loadbearing structure is a result of a wide-range discussion on appropriate strategies for refurbishment, restoration, conservation and preservation corresponding to location and significance of the historic bridge. The reconstruction increased durability and provides a long service life of the historical bridge and protection against harmful effects for many years to come. The article outlines historical data, consequences of the controversial reconstruction in the second half of the last century. Effects of river flow, temperature, and moisture and their influence on needful repairs are considered. Stages of reconstruction are presented; in the first stage, strengthening of foundations of bridge piers is described including historical background and impact of river flow on subgrade of piers. Ways of repairs and reconstruction of the bridge deck, its draining, and other related bridge elements are shown as a part of the second stage of reconstruction.
\end{abstract}

Keywords: bridge deck, draining, foundations, masonry bridge, reconstruction, stone masonry, temperature effects.

\section{Introduction}

Recently, a precious historical monument Charles Bridge (Fig. 1) in Prague has been reconstructed. Reconstruction of the exceptional structures is a complicated task. The Charles Bridge incorporates two features - it is both a structure with traffic function and a cultural and historical monument with precious medieval masonry and valuable sculptural decoration. Thus, all actions related to strengthening and repairing of the bridge had to be performed considering its significance and historical, cultural value.

In preparation for restoration, approaches of structural engineers and conservationists interfered. The conservationists account the bridge a historical monument, and structural engineers understand the bridge as a communication and connection of the riverbanks, which must sustain loads due to traffic or pedestrians. Nevertheless, the consensus prevailed that the repairs and restoration must respect the original design concept, historic materials, and construction techniques and the design of the intervention must be scientifically linked to the previous detailed diagnosis and reliability assessment of the structure. The historical and cultural value must be considered and the life cycle of the Charles Bridge must be enlarged despite modifying of the bridge use, as it happened in 1908 when the tram traffic was cancelled and later in 1965 when the bridge was closed to all traffic and it became entirely pedestrian bridge.

Site survey and investigations revealed common issues typical for historic masonry structures (Lourenco 2002): lack knowledge on the construction sequence, missing information about the inner core of the structure, extended construction period and related considerable variability of mechanical properties resulting both from a different age of structural parts and different sources of natural materials. Masonry arch bridge is a complex structure; the structural form of the bridge and all types of loads including temperature and moisture affect the behaviour. The combination of all effects cannot be accounted in commonly used empirical analyses; only finite element models allow considering of three-dimensional structural response and provide real information on the bridge resistance (Fanning et al. 2001).

The restoration was preceded and accompanied by detailed scientific analysis as an investigation into fields of heat and moisture transport, assessment of the sandstone masonry bricks and mortar state, structural analysis of the 
bridge behaviour and effects of various conditions on the bridge reliability.

\section{History and description}

Charles IV of the Luxembourg Dynasty, King of Bohemia, Germany, and Italy and Holy Roman Emperor commissioned the bridge to replace the old Judith Bridge, which has been damaged by the flood. The newly built bridge was constructed grand-scale; the spans and rises of arches are greater, the bridge deck level is four to five meters higher compared to the Judith Bridge. The Charles Bridge has 16 arches with span 16.62 to 23.88 meters and width cca $10.5 \mathrm{~m}$; the total length is $515.76 \mathrm{~m}$.

The foundation stone was laid in 1357. The first master, builder and constructor of the bridge was Otlin (Master Otto from Prague). After his death, managing of the construction took a Swabian builder Peter Parler, who was responsible also for building the St. Vitus Cathedral at Prague Castle.

During its history, the bridge suffered from floods many times. Just ten years after the bridge construction began, in 1367, one of the piers of the as-yet-uncompleted structure was destroyed by flooding.

In 1432 during floods, the bridge was ruptured at three points, and five of its piers were severely damaged. More harm befell Charles Bridge in 1784 when pieces of broken rafts and ice blocked the arches and the water flushed away a military guardhouse standing of the pier-head. The flood in 1890 washed away two bridge piers (No. 5 and No. 6) (overview of piers numbering - Fig. 2) and three arches.

In the last big flood in 2002, the bridge survived without severe damages.

The bridge has been remedied, repaired and reconstructed several times during its life. For example, after the floods in 1784, ice guards and wooden sheet piles were installed to shield the bridge piers. Restoration after floods in 1890 was accompanied by disputes about the way to recovery. One variant suggested building only two arches instead of three ruined ones, as it would increase a flood protection by increasing the flow profile of the bridge. Fortunately, this variant was rejected and the bridge is preserved in its original form.

Major reconstruction was carried out in 1966-1975 in four stages. The bridge was strengthened by a reinforced concrete layer (without expansion joints), covered by a bituminous water-proofing insulation, which had low durability and after cca 10 years it was insufficient for preventing water and salt penetration. The deck was paved with granite cubes laid in cement mortar.

To a large extent, ashlar blocks of stone piers, arches and facial walls and railings were replaced. However, the new sandstone ashlars had much worse quality than the original ones.

Only eleven years after the extensive reconstruction further replacement of sandstone blocks had to be carried out, mainly in spandrel walls. Some defect blocks were repaired just by cutting of part of the face out of the masonry and covered with thinner sandstone seals connected by injection with high strength cement mortar. The improper use of cement-based grout to fix newly inserted ashlars caused problems, because the hardened cement paste makes a barrier to water, having permeability much lower than the original mortar and furthermore the grout is much stiffer than original quality mortar with hydraulic lime.

Since 80ties, a new remedy of the Charles Bridge was discussed. Many expert opinions, many research reports were drafted (Drozd, Krizek 2003). They resulted in a plan of reconstruction scheduled in 3 phases. The main aims were providing the structural function of the bridge, restoring the loadbearing capacity and stability of the bridge and preventing further degradation.

The planning of remedial works was supported by investigations, monitoring in situ, analyses and experiments. The failures and defects had to be documented, evaluated; the causes of defects had to be eliminated or minimized their adverse influence. Hydrological events and the effects of temperature were monitored and analysed, mineralogical and petrographic surveys were conducted.

\section{Hydrology and geological survey of the river}

The river flow substantially affects the stability of the bridge structure. It was considered by the medieval builders of the bridge; they designed a suitable arrangement of the bridge ground plan so, that the river flow goes perpendicularly to the bridge longitudinal axes and the bridge piers minimally prevent the water flow. Also, it must be considered in the design of bridge foundations overhaul (unclear meaning). Experience confirms that failure of shallow foundations occurred due to deep potholes around and beneath the foundations of the piers, which lost stability and fell into the river.

Impacts of floating solids and ice floe on the bridge structure are essential components of the structural loads, particularly for its repeated action, which might cause a dynamic effect on the bridge structure. During spring thaw large floes and big floating bodies (tree trunks, wooden hut and cottages) impact the bridge structure, the

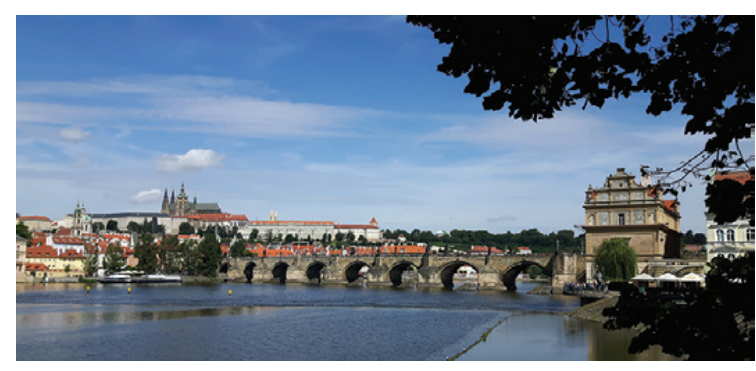

Fig. 1. Charles Bridge and Prague Castle panorama

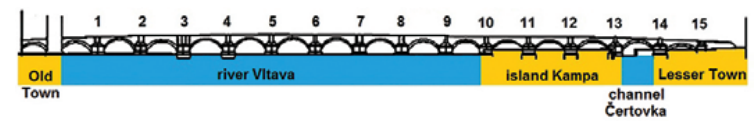

Fig. 2. System of bridge pillars numbering 
force resulting from impact reaches value $270 \mathrm{kN}$. Recurrent strokes on the bridge structure endanger the stability of the bridge vaults.

The average flow of Vltava River is $148 \mathrm{~m}^{3} / \mathrm{s}$. During the floods in August 2002, the flow was $5300 \mathrm{~m}^{3} / \mathrm{s}$ (Sklenár et al. 2007; Zeman et al. 2004). In such floods, there is a threat of clogging of the bridge arches and overtopping the bridge, which would lead to the collapse of stone railing and overthrow of the statues. An essential preservation of blocking of the arches during floods is a long reach excavator, which is able to smash big floating bodies or carry them over the bridge.

In the context of 2002 floods, it was decided to protect the island Kampa, which is also bridged by the Charles Bridge, by floodwalls. Mathematical models served to analyse if the floodwalls would not adversely affect the Charles Bridge. The analyses showed that the flood protection of Kampa would increase the water velocity by $0.2 \mathrm{~m} / \mathrm{s}$; the highest velocity $3.3 \mathrm{~m} / \mathrm{s}$ are reached between piers 3-4, 4-5 and 5-6. Thus, narrowing the flow profile of the Vltava has no significant influence on the flow capacity of analysed part of the river and does not significantly increase the impact of the flood flow (Cihák et al. 2004; Witzany et al. 2008).

Geological profile in the area consists of sandy gravel terrace, which gradates into coarse gravel mingled with boulders of volume $1 \mathrm{~m}^{3}$ or more. Under these gravels at a depth of 6-8 meters below the riverbed is the bedrock formed by Ordovician shale.

\section{Temperature effects on the bridge structure}

Some studies suggested climatic loading as the primary cause of the actual damage to the structure; therefore, in that occasion, a measuring system (able to record temperature and moisture content and gradients at selected gauge points) was installed. The measurement devices provided yearly records, which were used as temperature cycle input for the numerical analysis. In Prague, the winter temperatures are often below $0{ }^{\circ} \mathrm{C}$ and summer values reach more than $30^{\circ} \mathrm{C}$ (Rímal 2006). The gradient of temperature between the surface and internal layer is also accounted as the possible reason of faults (Krejčí, Šejnoha 2015).

Masonry adapts to these "non-mechanical effects" through stresses in the structure and the interaction of the external layers with the rigid bridge body filler results in deformations and possibly in cracks. Charles Bridge is a multiple arch structure. The arches practically have no affect to each other; the piers are so massive that they are able to withstand the lateral loading of the arch even if the arch in the next span collapses. The fact that the existing stone structure is pervaded by cracks is an expectable reaction to the load and its changes during the 600 years of the bridge existence. The bridge was built very rigid; thickness of the arch crown (cca $1 \mathrm{~m}$ ) is much bigger than minimal nominal thickness considering the span (16.7$23.38 \mathrm{~m}$ ) and the rise-over-span ratio (1/3.2). The flexural rigidity is increased by parapet walls and filling masonry. The cracking in the structure started at first volumetric changes caused by temperature - primarily in the mortar in joints and later in stone blocks (Zeman et al. 2008). Cracking of the structure is typical behaviour considering high structural stiffness.

Nowadays the state of the structure is stabilized, and it is not advisable to change the stress distribution and to jeopardize additional cracking. Cracks significantly influence the thermal expansion of stonework and related deformations. The structure cannot be analysed as one homogeneous body - the analysis must be based on nonlinear mechanics theory. The first consequence resulting from this theory is a significantly reduced stiffness of the masonry after formation of cracks and the second is the reduction of the average coefficient of thermal expansion. The non-linear behaviour of the structure is also the answer to question how the bridge withstands cyclic loading by extreme temperatures. Detailed non-linear analysis proved the above statements (Zeman et al. 2008). The analysis also determined the allowable loading of the bridge by moving load of weight 320 tons for $0.5 \mathrm{~m}$ distance of the vehicle from the masonry railing.

\section{Foundations of the bridge}

There is no historical documentation on original foundation during construction in the $14^{\text {th }}$ century.

There is assumption that the bridge was founded on the adapted riverbed. In the Middle Ages flat riverbank decreased water level especially in dry seasons so, that former teamsters forded safely across the river and according to historical reports, Vltava could have been crossed dry-shod. Thus, it was possible to divert the flow of the river and in the area under the foundation of the future piers manually remove sediments up to sandy-gravel or gravel layer. On treated area (foundation base), a layer of hydraulic mortar around the perimeter of the foundation was spread and the Carboniferous arkoses blocks were laid in the mortar. Among the blocks the filling masonry was successively built.

Most pier foundations were repaired, mostly in connection with damage to the piers during floods.

Collapsed parts of the pier were repaired so, that along the perimeter of collapsed part millstones (round dressed stones with a diameter of $0.8-1.0$ meters and 0.25 meters thick) were placed directly on the adjusted riverbed and connected with iron u-shaped ties sealed with lead. On the base, stone masonry was built. If the potholes were deeper (the depth of some potholes reached $5.4 \mathrm{~m}$ ), short wooden piles were driven in the gravel, and at the top, the piles were tied together by the oak grid. The millstones were laid in crossings of oak beams. The base for the laying of masonry was in some cases made from planks with thickness $15 \mathrm{~cm}$ to $20 \mathrm{~cm}$ and a mortar layer.

The inner space inside peripheral masonry was filled with inferior quarry sandstone masonry.

Piers No. 5 and No. 6 which were damaged by a flood in September 1890, are founded on iron caissons embedded $0.65 \mathrm{~m}$ in the bedrock (Masopust 2008). 
After the floods in 2002, a thorough diving survey was conducted. Surprising was the finding that most foundations of the piers remained in an acceptable condition. Just the mortar in joints was washed out, and there were deep potholes in front of and behind the bridge and between the piers. A damage of original protecting envelope from oak sheet piles of foundations of pier 8 and 9 was revealed.

\section{Remedial works and repairs of historical Charles Bridge}

\subsection{First stage of the remedial works}

Repairing of the foundations of piers 8 and 9 was the objective of the first stage of the primary reconstruction. Deep potholes between the piers were filled with rubble quarry stones with weight $40-200 \mathrm{~kg}$. New envelopes of foundations 8 and 9 were built. New protective envelopes have no connection with the original envelopes; the created space in between, is filled with rough stones injected with cement grout. The outer protecting envelope is composed of Larsen III sheet piles vibro-driven 1 meter in the bedrock, and below the bridge arches, where vibro-driving was impossible, flat sheet piles ARBED AS 500-12 were used.

The piles Larsen were vibro-driven in pre-drilled holes of $400 \mathrm{~mm}$ diameter filled with clay-cement mix. The ARBED sheet wall is four meters high and fixed in the bedrock via jet grouting columns of $0.6 \mathrm{~m}$ diameter. The top of the protecting envelope is covered by $0.5 \mathrm{~m}$ thick reinforced concrete slab.

A dynamic response was measured during remedial works. The speed of vibrations was controlled - the maximum measured speed $1.445 \mathrm{~mm} / \mathrm{s}$ was within the allowed limits.

\subsection{Second stage of remedial works}

Another compelling reason for reconstruction was damage due to rainwater leakage and de-icing chemicals. Contamination of the structure by salts activated chemical, biochemical and physical degradation processes, what concerned relatively new stones added during the recent interventions (Korenska et al. 2016; Prikryl et al. 2011).

After comprehensive studies, a considerate moderate remediation was prepared with minimal intervention into historical structures, which included reconstruction of a bridge deck waterproofing system and installation of an efficient bridge draining. Furthermore, new public gas lamp lighting (Fig. 3) and night lighting of the bridge and navigation signs were installed. The fibre optic cable was laid, and security camera system supplemented. Sensors and cables for measuring of temperature gradient and moisture in the body of the bridge were mounted. The stone railing was repaired, and damaged stone blocks of the railing were replaced. In this stage of remediation, some mistakes of previous intervention were corrected.

Repairs to the bridge deck were carried out without closing the bridge. Pedestrian traffic was preserved on one-half of the bridge. Works were carried out in sections.

Layers of the bridge deck are successively dismantled and removed to a depth of $500 \mathrm{~mm}$. Newly laid pavement layers consist of a concrete base and a screed layer, sprayed insulation coating with a protective layer of concrete and a layer of granite cubes laid in the sand solidified with lime. The sprayed coating is membrane isolation from the two-component material based on methacrylic resins. The insulation is attached to the vertical face of the parapet railing (height $200 \mathrm{~mm}$ ), and there it is fixed in the milled groove, which runs $20 \mathrm{~mm}$ below the surface of the paving.

The paving granite cubes had to be appropriately compacted in the sand bedding. This technology of paving has proven to better than laying of the cubes in concrete screed which had been applied in the previous repair of the bridge deck. First, the stiff layer of concrete would require dilatation of the paving and second the cubes fixed in concrete were often tumbled out.

On sides, the new paving layers are separated from the parapet walls except for the sprayed insulation, which is attached to the bottom of the railing.

\subsection{The draining of the bridge}

In the $14^{\text {th }}$ century, the drainage of rainwater was provided by 24 stone gargoyles, which preserved. Current reconstruction retains draining water from the bridge deck through gargoyles (Fig. 4) from medieval times.

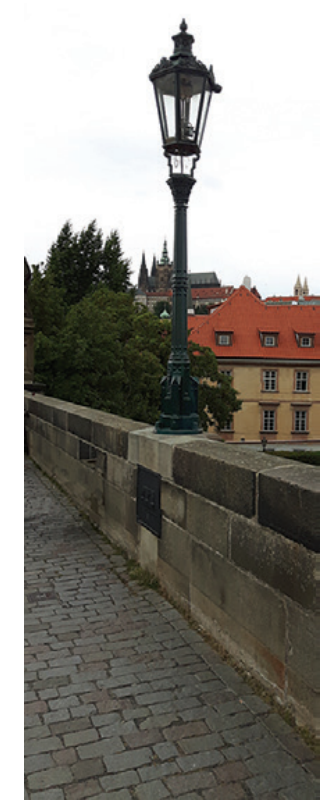

Fig. 3. New gas lamp

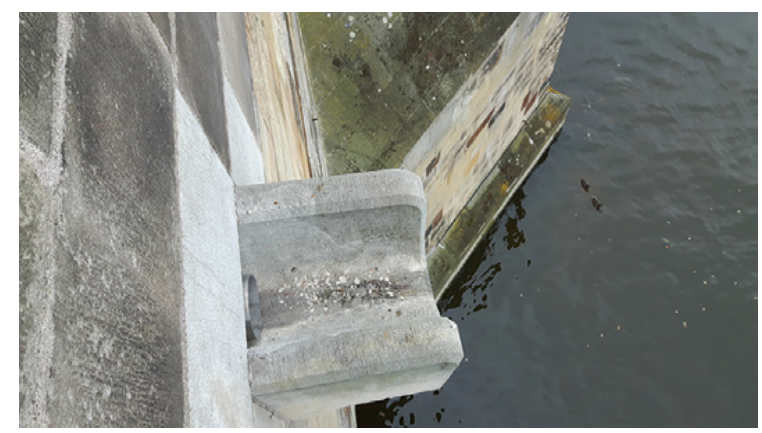

Fig. 4. Gargoyle with the new drainage system outlet 
The pavement has transversal sloping 2 per cent, which creates two valleys in the distance 1.5 meters from the parapet. Rotatable bridge gully of cast iron funnels the rainwater by a lateral rust-stable outlet directly towards the gargoyles. Water seeps through joints in the pavement, is drained from the surface of the insulation.

For drainage of the insulation, a drainage mat is glued point wise on the surface of the insulation. The drainage mat is created from HDPE (high-density polyethylene) geonets with the fibres at an angle of $60^{\circ}$ with one-sided geotextile lamination.

The depth of the protective concrete layer is $80 \mathrm{~mm}$. This relatively thin layer incorporates all present-day networks in plastic installation ducts; i.e., piping and control cables for gas-lighting, cables of bridge night lighting and lighting of navigation signs, optic cables of the security system (Fig. 5).

The repair of the bridge deck was accompanied by repair of the stone railing. It was essential for fixing the insulation edge (the railing is used as an attic) and safety of people. The railing masonry has been rebuilt several times in the past, and it had probably various forms. The railing represents a wide range of different technologies, which are less than 100 years old.

The stone blocks are of different petrographic origin; there are various types of sandstone of different quality.

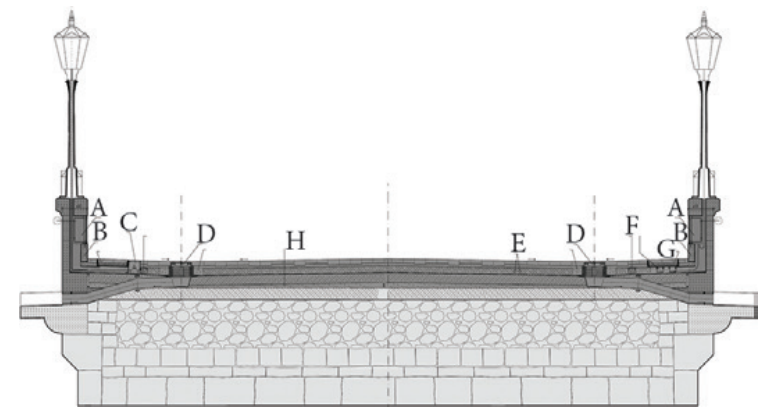

Fig. 5. Bridge cross section of the arch crown

(A - electrical enclosure box, B - stone cover of electric cables, $\mathrm{C}$ - gas supply switch, D - rotatable bridge gully, E - cable raceway of the security camera system, $\mathrm{F}$ - gas supply in conduit, $\mathrm{G}$ - electric cables in conduit, $\mathrm{H}$ - layers of the bridge deck: granite paving - layer of sand solidified with lime - protective concrete layer - drainage mat - sprayed insulation - screed concrete - geotextile - reinforced concrete layer from previous reconstruction) (Tvrzník 2008)

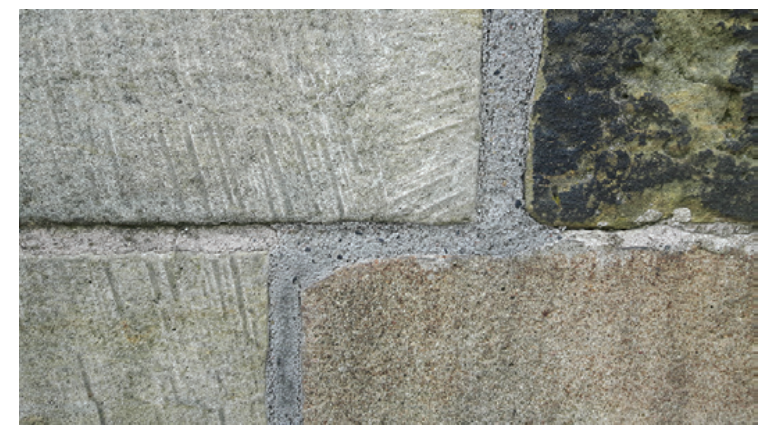

Fig. 6. Dilatation joint filled with polyurethane sealer and surface finish
The great diversity of types of stones and the colour differences are due to the various types of degradation processes of stones surfaces and different degradation rate (Drdácký, Slízková 2008).

Some repairs in the past were performed only by removal of disturbed surface part of the stone to a depth of $15 \mathrm{~cm}$ and inserting a flat plate, sometimes across joints of the masonry. This method of repair was done both from the bridge deck side and the outer side, thus in some parts of the railing, the masonry bond of the inner side of railing does not correspond with the outer appearance.

Inappropriate use of cement mortar of strength cca $50 \mathrm{MPa}$ applied in the previous repair contributed to the degradation of stones. The condensed water increases the humidity of the stone and thereby decreases its strength; frost causes further degradation.

On the other hand, there are joints with almost no functional connection stones. They are filled with degraded crushed mortar, and usually, the stones shifted against each other. Sometimes small vegetation grew in such joints.

The parapet wall was dismantled to the bridge deck level. The stone blocks connected with hydraulic lime mor$\operatorname{tar}$ (strength cca $5 \mathrm{MPa}$ ) were parted by wooden wedges. The cement mortar strength is about two or three times higher than the strength of sandstones. The cement mortar held the stones firmly together, and therefore the stoned had to be separated by grinding wheel.

After separating, the stones were cleaned and a designated committee chose which stones would be placed back in their original position and which would be replaced by new stones from quality quartz sandstone. The stone blocks are laid in a stretcher bond; i.e., across the whole width of the parapet $400 \mathrm{~mm}$. Unique low strength hydraulic lime mortar is used.

Deformations of the parapet masonry are tied with deformations of the whole bridge. Because of the heat accumulation, the response to thermal changes of the bridge differs from the behaviour of the parapet. Therefore, dilatation joints had to be made in the brickwork. The joints are filled with polyurethane sealer, which is for aesthetic reasons spread by fine gravel (Fig. 6).

The next phase, during which masonry casing of the bridge will be repaired, will take place in the future years. Pontoons will be used for the the repair works, and the pedestrians on the bridge will not be limited.

Nevertheless, it must be considered that the stone masonry is subjected to environmental effects and other external influences and it will have to be repaired continuously. The plan of maintenance of the bridge was prepared based on the knowledge gained during reconstruction, and it has been submitted to municipal authorities. Monument of such importance deserves regular care.

\section{Conclusions}

1. The authors are convinced that the repairing of the Charles Bridge respected the original materials and construction techniques to the highest possible extent. The 
design of the bridge repairs was based on analysis of the multi-decade response of an old masonry bridge, diagnosis and assessment of damages, failures and deterioration processes related to materials, environment, climate, structural arrangement and detailing with regard to heritage, historical and structural aspects.

2. The gentle way of remedial works with minimal intervention in the loadbearing structure is a result of a wide-range discussion on appropriate strategies for refurbishment, restoration, conservation and preservation corresponding to location and significance of the historic bridge. The ways to increase durability and provide a long service life of the historical bridge were considered ensuring that the Charles Bridge would be protected against harmful effects for many years to come.

\section{Acknowledgement}

Financial support from the Grant Agency of the Czech Republic through Grant No. 16-04454S is gratefully acknowledged.

\section{References}

Cihák, F.; Satrapa, L.; Fosumpaur, P. 2004. Analysis of Flow Profiles between Piers of Charles Bridge in Prague during Flood. Technical Report No CVUT/2004-000. Czech Technical University in Prague. 11 p. (in Czech)

Drdácký, M.; Slízková, Z. 2008. Analysis of Mortar and Stone Samples Extracted from the Charles Bridge in Prague. Technical Report No 313211. ÚTAM AV ČR. Prague, Czech Republic. 60 p. (in Czech)

Drozd, K.; Krizek, V. 2003. Problems of Charles Bridge Repair, Journal Geotechnika 2: 3-6. (in Czech)

Fanning, P. J.; Boothby, T. E.; Roberts, B. J. 2001. Longitudinal and Transverse Effects in Masonry Arch Assessment, Construction and Building Materials 15(1): 51-60. https://doi.org/10.1016/S0950-0618(00)00069-6

Korenska, M.; Manychova, M.; Pazdera, L.; Pospisil, K. 2016. Structural Integrity of Stone Blocks from Charles Bridge in Prague, International Journal of Architectural Heritage 10(1): 1-8. https://doi.org/10.1080/15583058.2013.834088

Krejčí, T.; Šejnoha, J. 2015. Evolution of Temperature and Moisture Fields in Charles Bridge in Prague: Computational Prediction and Measurements, International Journal of Architectural Heritage 9(8): 973-985.

https://doi.org/10.1080/15583058.2014.893461
Lourenco, P. B. 2002. Computations on Historic Masonry Structures, Progress in Structural Engineering and Materials 4(3): 301-319. https://doi.org/10.1002/pse. 120

Masopust, J. 2008. Reconstruction of Pier Foundations of the Charles Bridge in Prague, in Proc. of the $6^{\text {th }}$ International Conference on Case Histories in Geotechnical Engineering, 1116 August 2008, Arlington, United States of America. Missouri University of Science and Technology, 1-7.

Prikryl, R.; Weishauptová, Z.; Novotná, M.; Prikrylová, J.; Štastná, A. 2011. Physical and Mechanical Properties of the Repaired Sandstone Ashlars in the Facing Masonry of the Charles Bridge in Prague (Czech Republic) and an Analytical Study for the Causes of Its Rapid Decay, Environmental Earth Sciences 63 (7-8): 1623-1639. https://doi.org/10.1007/s12665-010-0819-5

Rímal, J. 2006. The Measurement of Temperature Gradients of Charles Bridge in Prague, in Proc. of International Workshop: Physical and Material Engineering 2006. Ed. by Palacková, A. 5-7 September, 2006, Bratislava, Slovakia, 218-221, ISBN 80227-2467-X.

Sklenár, P.; Zeman, E.; Špatka, J.; Tachecí, P. 2007. Flood Modelling and the August 2002 Flood in the Czech Republic, Flood Risk Management in Europe. Advances in Natural and Technological Hazards Research 25: 253-274. https://doi.org/10.1007/978-1-4020-4200-3_14

Tvrzník, V. 2008. Repair of the Charles Bridge, in Proc. of the Conference Beton 08: selected papers, Ed. Kohoutková, A. 23 - 24 September 2008, Prague, Czech Republic: CVUT: 139-152.

Witzany, J.; Cejka, T.; Zigler, R. 2008. Failure Resistance of Historic Stone Bridge Structure of Charles Bridge. II: Susceptibility to Floods, Journal of Performance of Constructed Facilities 22(2): 83-91. https://doi.org/10.1061/(ASCE)0887-3828(2008)22:2(83)

Zeman, E.; Hrncír, V.; Sklenár, P. 2004. Hydrodynamical Modelling Used in Flood Plain Zoning and Designation - Plans and Reality during the Flood in 2002 in the Czech Republic, in Proc. of the 6th International Conference on Hydroinformatics, 21-24 June 2004, Singapore. World Scientific. https://doi.org/10.1142/9789812702838_0026

Zeman, J.; Novák, J.; Šejnoha, M.; Šejnoha, J. 2008. Pragmatic Multi-Scale and Multi-Physics Analysis of Charles Bridge in Prague, Engineering Structures 30(11): 3365-3376. https://doi.org/10.1016/j.engstruct.2008.05.012

Received 10 November 2016; accepted 20 September 2017 